\title{
Gonadosomatic Index and Testis Morphology of Common Carp (Cyprinus carpio) in Rivers Contaminated with Estrogenic Chemicals
}

\author{
Amin HASSANIN ${ }^{1}$, Sachi KUWAHARA ${ }^{1)}$, NURHIDAYAT ${ }^{1}$, Yasuhiro TSUKAMOTO $^{1)}$, Kazushige OGAWA ${ }^{1)}$, \\ Kazuya HIRAMATSU ${ }^{2)}$ and Fumihiko SASAKI ${ }^{1) *}$ \\ ${ }^{1)}$ Laboratory of Veterinary Anatomy, Graduate School of Agriculture and Biological Sciences, Osaka Prefecture University, Sakai, Osaka \\ 599-8531 and ${ }^{2)}$ Osaka Prefectural Freshwater Fish Experiment Station, Kiyamotomachi 10-4, Neyagawa, Osaka 572-0088, Japan
}

(Received 8 May 2002/Accepted 2 July 2002)

ABSTRACT. To study the effect of estrogenic chemicals on fish, the gonadosomatic index $(\mathrm{GSI}=$ [testis weight/body weight $] \times 100)$ and testis histology of mature common carp (Cyprinus carpio) from 2 contaminated sites (Ishizu and Wada rivers, Osaka) and a control site were examined between June 1998 and March 2001. The concentration of nonylphenol, bisphenol A and 17 $\beta$-estradiol in the Ishizu river was 3-4 times higher than in the Wada river. In the pre-breeding and breeding seasons, there were no significant differences in body weight among carp from the 3 sites, the body weight of Ishizu river carp being significantly lower $(p<0.05)$ than that of Wada river fish only in the post-breeding season. The GSI and testis weight in fish from the Ishizu river were significantly lower $(p<0.05)$ than in control fish during all phases of gonadal cycle and lower than in Wada river fish in the pre-breeding and post-breeding season. No histological abnormalities were found in the testes of the males examined. Histological observation of the testes revealed a delay in the onset of spermatogenesis in fish from the Ishizu river compared with those from the other sites. These results clearly imply that the estrogenic chemicals in the Ishizu river adversely affect the testis development of the fish.

KEY WORDS: carp, estrogenic chemical, gonadosomatic index, histology, testis.

J. Vet. Med. Sci. 64(10): 921-926, 2002

There is growing evidence in support of the claim that contamination of a wildlife population with estrogenic chemicals can disturb the reproductive function of vertebrates $[6,7,12]$. Many researches have been focused on fish, since as aquatic inhabitants they receive sewage or industrial effluent and agricultural runoff containing estrogenic chemicals $[5,14,30]$. In fish, estrogenic responses have been associated with exposure to pesticides $[3,35]$, pulp mill effluents [23, 29, 34], plasticizers [19] and sewage effluent $[2,17,31]$. Abnormalities have also been reported in the male reproductive system of fish living in water polluted by sewage or industrial chemicals $[12,25]$. Studies on the male teleost revealed changes including induced vitellogenin production $[5,13,14,20]$, hermaphroditism as evidenced by the presence of both testicular and ovarian tissues $[8,10,11,18,31]$, reduced testis size [20] and reduced plasma androgen concentrations together with delayed sexual maturity [26].

Some information is known on the effect of estrogens and estrogenic chemicals on the carp testis, and their relation to seasonal changes in testis morphology. Three-month exposure to a sublethal dose of 4-tert-pentylphenol or $17 \beta$-estradiol causes progressive disappearance of spermatozoa and spermatogenic cysts, and reduces the seminiferous tubule diameter, in mature male carp [11]. Ovo-testes were found in juvenile carp exposed to xeno-estrogens during sexual differentiation $[8,9]$. However, a field study on adult crucian carp (Carassius carassius) living in a pond containing

\footnotetext{
* Correspondence to: Prof. Dr. Sasaki, F., Laboratory of Veterinary Anatomy, Graduate School of Agriculture and Biological Sciences, Osaka Prefecture University, Sakai, Osaka 599-8531, Japan.
}

treated pulp mill effluent showed no gonadal deformation or feminization of male gonads [23]. It is therefore important to study the testis of mature male carp (Cyprinus carpio) living in rivers polluted by sewage-treatment works and industrial effluents in order to settle whether estrogenic chemical contaminants cause endocrine disruption. Of fish inhabiting fresh water, the carp is suitable for monitoring long-term adverse effects of endocrine disrupters on gonads because carp can survive in highly polluted water. The present field study examines the effects of estrogenic chemicals on the testis of mature male carp.

\section{MATERIALS AND METHODS}

Fish: The fish used in this study were 115 mature male carp (Cyprinus carpio), 3-5 years old, and their age was estimated from the annual rings in the scales [32]. The fish were collected from three sites using a casting net. Fiftyfour fish were caught from the Ishizu river and 26 fish from the Wada river (Fig. 1), and 35 fish from the outdoor ponds of the Osaka Prefecture Freshwater Fisheries Experimental Station (OPFFES) were used as control. The fish in the OPFFES were fed with commercial fish food (Nippon Formula Feed Mfg., Osaka). They were sampled from June 1998 till March 2001. The body weight of each fish was recorded and the testes were removed and weighted. Their size was specified as a percentage of total body weight (gonadosomatic index: GSI $=$ [testis weight/body weight $] \times$ 100). In Japan, almost all wild animals show seasonal variations in reproduction and behavior [24]. Carp fish spawn from the end of April to July [21, 28]. We therefore tentatively grouped these male carp into three phases as follows: 


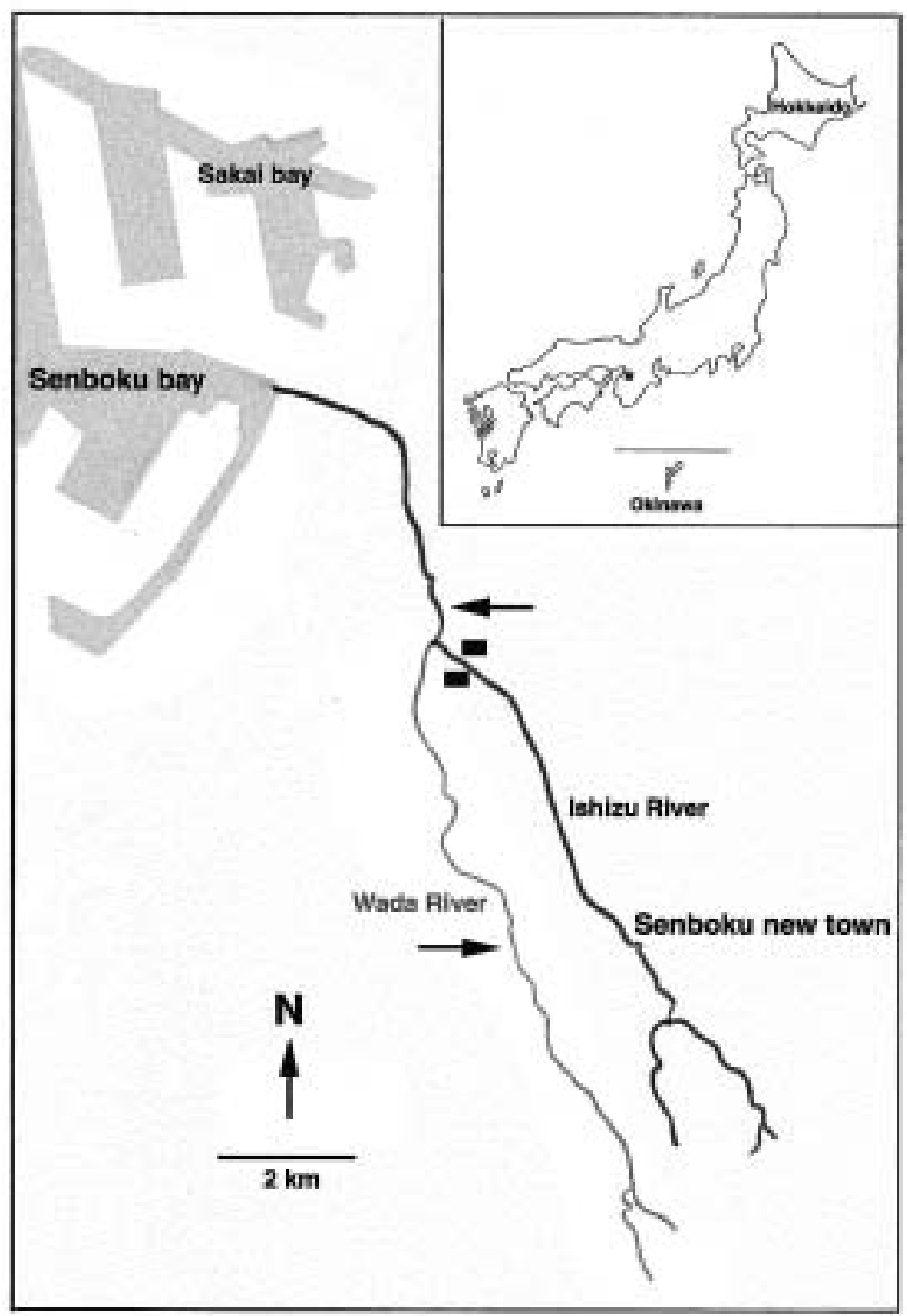

Fig. 1. Map of Sakai city showing the Senboku new town area with the two collection river sites, on the Ishizu and Wada rivers. (ם) Sewage treatment works, $(\rightarrow)$ Sampling sites. The Ishizu river was listed as contaminated site, receiving effluent from two sewage-treatment works associated with Senboku new town and industrial effluents.

the pre-breeding season (February-March), the breeding season (May-July) and the post-breeding season (AugustNovember). The Ishizu and Wada rivers are similar environment. They run abreast until the Wada river joins the Ishizu river. At the sampling site, both rivers are $20 \mathrm{~m}$ wide and 20-50 $\mathrm{cm}$ deep.

Chemical analysis: Water samples from the sampling sites on the Ishizu and Wada rivers were analyzed chemically for the presence of three estrogenic chemicals, nonylphenol, bisphenol A and 17 $\beta$-estradiol. Analysis took place at Nippon Steel Technoresearch (Osaka) according to the method specified by the Water Quality Management
Division of Japan Environment Agency [15].

Testis histology: Fragments $\left(1 \mathrm{~cm}^{3}\right)$ from the middle part of the testis were fixed in Bouin's solution for 20-24 hr, and stored in $70 \%$ ethanol ready for further histological processing. After dehydration in graded ethanol and embedding in Tissue Prep (Fisher Scientific, Pittsburgh, PA, U.S.A.), 4 $\mu \mathrm{m}$ sections were cut, stained with haematoxylin and eosin, and observed using an optical microscope.

Statistical analysis: Differences in body and testis weights, as well as GSI between the fish, were tested by Student's $t$-test, and are considered significant at the $p<0.05$ level. GSI was also tested by Smirnov's elimination test. 
Table 1. The body weight (kg.), testis weight (g.) and GSI of mature carp (Cyprinus carpio) from control site, Ishizu river and Wada river in the different reproductive seasons

\begin{tabular}{|c|c|c|c|c|c|c|c|c|c|c|c|}
\hline \multirow{2}{*}{$\begin{array}{l}\text { Reproductive } \\
\text { Season }\end{array}$} & \multicolumn{4}{|c|}{ Control carp } & \multicolumn{3}{|c|}{ Ishizu river carp } & \multicolumn{4}{|c|}{ Wada river carp } \\
\hline & B.W.(Kg) & T.W.(g) & GSI & (n) & B.W.(Kg) & T.W.(g) & GSI & B.W.(Kg) & T.W.(g) & GSI & (n) \\
\hline Pre-breeding & $1.56 \pm 0.14$ & $124 \pm 18^{*}$ & $7.6 \pm 0.6^{*}$ & (11) & $1.43 \pm 0.07$ & $59 \pm 7$ & $4.1 \pm 0.4 \quad$ (19) & $1.61 \pm 0.15$ & $125 \pm 13^{*}$ & $7.7 \pm 0.3^{*}$ & (8) \\
\hline & $.37 \pm 0.13$ & $72 \pm 12$ & $5.1 \pm 0.7$ & (15) & $1.22 \pm 0.05$ & $27 \pm 5^{\dagger}$ & $2.2 \pm 0.3^{\dagger}(14)$ & $1.26 \pm 0.10$ & $30 \pm 6^{\dagger}$ & $2.4 \pm 0.4^{\dagger}$ & (7) \\
\hline Post-breeding & $1.51 \pm 0.19$ & $105 \pm 15^{*}$ & $7.3 \pm 1.0 *$ & (9) & $1.07 \pm 0.05$ & $34 \pm 5$ & $3.1 \pm 0.4$ & $1.36 \pm 0.09^{*}$ & $116 \pm 12 *$ & $8.3 \pm 0.5^{*}$ & (11) \\
\hline
\end{tabular}

Values are expressed as the mean \pm SE, numbers of carp are given in parentheses.

* $P<0.05$ compared with the value of the Ishizu river carp.

$\dagger P<0.05$ compared with the value of control carp.

\section{RESULTS}

Chemical analysis of study sites: The concentrations of nonylphenol, bisphenol $\mathrm{A}$ and $17 \beta$-estradiol in the Ishizu river were $0.70,0.20$ and $0.008 \mu \mathrm{g} / l$, respectively. These values were 3-4 times higher than those found in the Wada river $(0.24,0.06$ and $0.002 \mu \mathrm{g} / l$, respectively). There is no data about the estrogenic chemicals concentration in water of OPFFES.

Body and testis weights: The body and testis weights as well as GSI are shown in Table 1. There were no significant differences between the body weight of the three groups at any seasons, with the exception of difference between Ishizu and Wada river carp in the post-breeding season. Testis weight and GSI clearly changed according to reproductive season in all groups, reaching their peak values in the prebreeding season coinciding with the large accumulation of spermatozoa. Values decreased with spawning in the breeding season and then rose again in the post-breeding season. The testis weight and GSI of the Ishizu river carp were significantly lower $(p<0.05)$ than from the control site in all seasons, and lower than in Wada river carp in the pre-breeding and post-breeding seasons. Significant differences in testis weight and GSI value between Wada river carp and the control carp were found only in the breeding season.

Histology of the testis: The testes consist of large numbers of highly convoluted seminiferous tubules of various shapes and sizes. The intertubular spaces contain a few interstitial cells and blood vessels. Histological examination found no difference between the contaminated and control sites, and no pathological lesions were discerned. The testes exhibited two stages of maturity, spermiation (fully mature) and active spermatogenesis. In the spermiation stage, the luminae of the seminiferous tubules were filled with spermatozoa and occasionally contained spermatogenic cysts (Fig. 2a). In the pre-breeding season the spermiation stage occurred in almost all carp from the three sites, in the breeding from the Ishizu river and in the post-breeding season from Wada river and the control site. The active spermatogenesis stage is characterized by accumulation of a large number of spermatogonia B, spermatocytes and spermatids in the form of spermatogenic cysts, with some spermatozoa observed in the lumen of the tubules (Fig. 2b). In the breeding season the active spermatogenesis stage was sometimes observed in the testis of carp in the Wada river and the control site, and in Ishizu river carp in the postbreeding season (Table 2).

\section{DISCUSSION}

Based on a survey made by the Japan Environmental Agency (1999) on 42 kinds of environmental hormones, out of 123 rivers from Hokkaido to Okinawa prefectures, the Ishizu river contained a higher concentration of estrogenic chemicals [16]. Of the various estrogenic chemicals present in effluent that entered the Ishizu river, three were analyzed, natural estrogen (17 $\beta$-estradiol) and two xeno-estrogens (nonylphenol and bisphenol A), which are known to be estrogenic to fish and present in the aquatic environment [33]. The concentration of these chemicals in the Ishizu river was found to be 3-4 times higher than in the Wada river. The testes of the Ishizu river carp were much smaller than those of the Wada river carp and control fish. These results were in consistent with that reported for the testes of caged male trout exposed to water contaminated by sewage effluent in rivers in the United Kingdom [14]. We believe the concentration of estrogenic chemicals in both contaminated sites in the present study is considerably below the threshold $(0.1 \mu \mathrm{g} / l$ of the $17 \beta$-estradiol) needed to cause observable histological changes in the testes [11], but the observed concentrations could only cause endocrine disruption and delay maturational development of testes in the Ishizu river carp.

GSI is used as a biomarker for exposure of aquatic wildlife to environmental estrogens, since a correlation has been established in male fish between the inhibition of testicular growth and the potency of estrogenic compounds [4, 9, 22]. Field studies have reported that estrogenic chemicals decrease the GSI of exposed fish $[1,14,23]$. The decrease in GSI values of fish from the Ishizu river could be due to the combination of the differing estrogenic chemicals found in the sewage and industrial effluents discharged into this river. In the breeding season alone, testes and GSI in control carp were larger than those of the Wada river fish. This may be due to environmental differences between the two sites (pond or river; domestic or wild) and the influences of the estrogenic chemicals involved, or to other factors. Little is known about the effect of estrogenic chemicals on the histo- 


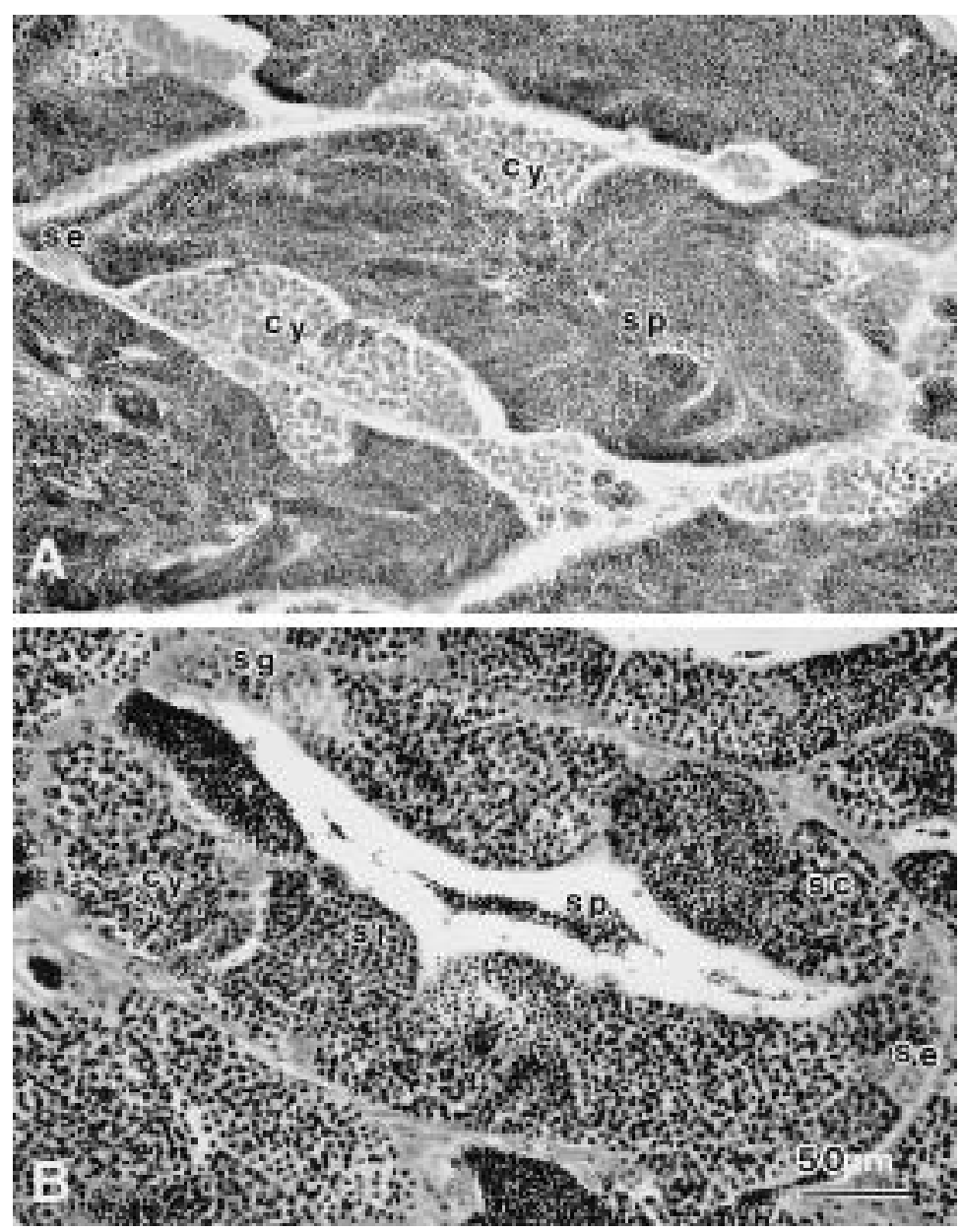

Fig. 2. Light micrographs of the testes of the Ishizu river male carp (Cyprinus carpio) showing two testicular maturation stages. (A) In the spermiation stage the lumen of the seminiferous tubule is filled with spermatozoa (sp), spermatogenic cysts (cy) and Sertoli cells (se). (B) In the active spermatogenesis stage, spermatogenic cysts (cy) contain spermatogonia (sg), spermatocytes (sc) and spermatides (st). Spermatozoa (sp) are present in the lumen and Sertoli cells (se) near the basal lamina. Bar $=50 \mu \mathrm{m}$.

Table 2. Numbers of mature male carp in the two stages of testicular maturation spermiation $(S p)$ and active spermatogenesis $(S g)$ in different reproductive seasons

\begin{tabular}{lcccccc}
\hline \multirow{2}{*}{ Reproductive season } & \multicolumn{2}{c}{ Control carp } & \multicolumn{3}{c}{ Ishizu river carp } & \multicolumn{2}{c}{ Wada river carp } \\
& $(S p)$ & $(S g)$ & $(S p)$ & $(S g)$ & $(S p)$ & $(S g)$ \\
\hline Pre-breeding & 10 & 1 & 19 & 0 & 8 & 0 \\
Breeding & 10 & 5 & 13 & 1 & 3 & 4 \\
Post-breeding & 9 & 0 & 15 & 6 & 10 & 1 \\
\hline
\end{tabular}

logical structure of mature male carp. We found that the testes of carp from the Ishizu and Wada rivers showed no pathological lesions or abnormalities, and the fish successfully reproduced in both rivers. These findings are consistent with a study conducted in adult crucian carp living in a pond contaminated with pulp mill effluent, where the testes revealed no sign of deformation or feminisation [23]. Experimentally, a high dose of estrogenic chemicals as $17 \beta$ estradiol and nonylphenol causes histopathological lesions in germ cells, spermatozoa and Sertoli cells [4, 11, 27]. These changes in the testicular structure are dependent on the estrogenic potency of the estrogenic chemicals, the stage 
of reproductive development of the fish, and the concentration of the chemicals in the water [20]. The concentration of $17 \beta$-estradiol, bisphenol A and nonylphenol in the Ishizu river was considerably below the threshold required experimentally to alter significantly the testis histology of mature carp. However, even at the lower concentration observed, as many other estrogenic chemicals contaminate the water in the Ishizu river [16], the combination of these chemicals has some effect on reproduction specifically, that is, (1) a considerable drop in cellular proliferation or testes growth, based on the reduction in the weight of the testis from the Ishizu river fish, and (2) delay in reaching the active spermatogenesis stage in the Ishizu river carp in the post-breeding season, rather than in the breeding season as in the control carp.

In conclusion, we have found a correlation between the concentration of estrogenic chemicals in these rivers and reproductive dysfunction of the male fish that are exposed to them. It appears that the concentration of estrogenic chemicals in the Ishizu river inhibits testes growth and delays testes maturation but produces no abnormal histological structures in the testes. Fish from the Wada river showed almost no effects on GSI or testicular structure.

ACKNOWLEDGMENT. The authors wish to thank Nippon Steel Technoresearch for the analysis of water in the Ishizu and Wada rivers.

\section{REFERENCES}

1. Andersson, T., Forlin, L., Hardig, J. and Larsson, A. 1988. Physiological disturbances in fish living in coastal water polluted with bleached kraft mill effluents. Can. J. Fish Aquat. Sci. 45: 1525-1536.

2. Batty, J. and Lim, R. 1999. Morphological and reproductive characteristics of male mosquitofish (Gambusia affinis holbrooki) inhabited sewage-contaminated water in New South Wales, Australia. Arch. Environ. Contam. Toxicol. 36: 301307.

3. Bitman, J. and Cecil, H.C. 1970. Estrogenic activity of DDT analogs and polychlorinated biphenyls. J. Agric. Food Chem. 18: $1108-1112$.

4. Christiansen, T., Korsgaard, B. and Jespersen, A. 1998. Induction of vitellogenin synthesis by nonylphenol and 17 betaestradiol and effects on the testicular structure in the eelpout Zoarce viviparous. Mar. Environ. Res. 46: 141-144.

5. Flammarion, P., Brion, F., Babut, M., Garric, J., Migeon, B., Noury, P., Thybaud, E., Tyler, C.R. and Palazzi, X. 2000. Induction of fish vitellogenin and alterations in testicular structure: preliminary results of estrogenic effects in chub (Leuciscus cephalus). Ecotoxicology 9: 127-135.

6. Folmar, L.C., Denslow, N.D., Rao, V., Chow, M., Crain, D.A., Enblom, J., Marcino, J. and Guillette, L.J. 1996. Vitellogenin induction and reduced serum testosterone concentration in feral male carp (Cyprinus carpio) captured near major metropolitan sewage treatment plant. Environ. Health Perspect. 104: 10961101.

7. Fry, D.M. 1995. Reproductive effects in birds exposed to pesticides and industrial chemicals. Environ. Health Perspect. 103: $165-171$.
8. Gimeno, S., Gerritsen, A., Bowner, T. and Komen, H. 1996. Feminization of male carp. Nature (Lond.) 384: 221-222.

9. Gimeno, S., Komen, H., Venderbosch, P. and Bowmer, T. 1997. Disruption of sexual differentiation in genetic male common carp, Cyprinus carpio, exposed to an alkylphenol during different life stages. Environ. Sci. Technol. 31: 2884-2890.

10. Gimeno, S., Komen, H., Gerritsen, A.M. and Bowmer, T. 1998. Feminisation of young males of the common carp, Cyprinus carpio, exposed to 4-tert-pentylphenol during sexual differentiation. Aquat. Toxicol. 43: 77-92.

11. Gimeno, S., Komen, H., Jobling, S., Sumpter, J. and Bowmer, T. 1998. Demasculinisation of sexually mature male common carp, Cyprinus carpio, exposed to 4-tert-pentylphenol during spermatogenesis. Aquat. Toxicol. 43: 93-109.

12. Guillette, J., Timothy, S.G., Masson, G.R., Matter, J.M., Percival, H.F. and Woodward, A.R. 1994. Developmental abnormalities of the gonad and abnormal sex hormone concentrations in juvenile alligators from contaminated and control lakes in Florida. Environ. Health. Perspect. 102: 680-688.

13. Harries, J.E., Sheahan, D.E., Jobling, S., Matthiessen, P., Neall, P., Roultedge, E., Rycroft, R., Sumpter, J. and Taylor, T. 1996. A survey of estrogenic activity in UK inland waters. Environ. Toxicol. Chem. 15: 1993-2002.

14. Harries, J.E., Sheahan, D.E., Jobling, S., Matthiessen, P., Neall, P., Sumpter, J., Taylor, T. and Zaman, N. 1997. Estrogenic activity in five United Kingdom rivers detected by measurement of vitellogenesis in caged male trout. Environ. Toxicol. Chem. 16: 534-542.

15. Japan Environmental Agency. 1998. Analytic Methodology: Provisional Surveillance Manual for Endocrine Disruptors. Water Management Division, Tokyo, Japan (in Japanese).

16. Japan Environmental Agency. 1999. Proceedings of the First Project Meeting on Endocrine Disruptors. Tokyo, Japan (in Japanese).

17. Jobling, S. and Sumpter, J. 1993. Detergent components in sewage effluent are weakly estrogenic to fish: an in vitro study using rainbow trout (Oncorhynchus mykiss) hepatocytes. Aquat. Toxicol. 27: 361-372.

18. Jobling, S., Nolan, M., Tyler, C.R., Bright, Y.G. and Sumpter, J. 1998. Widespread sexual disruption in wild fish. Environ. Sci. Technol. 32: 2498-2506.

19. Jobling, S., Reynolds, T., White, R., Parker, M.G. and Sumpter, J. 1995. A variety of environmentally persistent chemicals, including some phthalate plasticizers, are weakly estrogenic. Environ. Health Perspect. 103: 582-587.

20. Jobling, S., Sheahan, D., Osborne, J.A., Matthiessen, P. and Sumpter, J. 1996. Inhibition of testicular growth in rainbow trout (Oncorhynchus mykiss) exposed to estrogenic alkylphenolic chemicals. Environ. Toxicol. Chem. 15: 194-202.

21. Kawamoto, N. 1967. Studies of Fish-Farming. pp. 1-804, Kosheisha Koseikaku, Tokyo (in Japanese).

22. Komen, J., Lodder, P.A.J., Huskens, F., Richter, C.J.J. and Huisman, E.A. 1989. The effect of oral administration of $17 \alpha-$ methyltestosterone and $17 \beta$-estradiol on gonadal development in common carp, Cyprinus carpio L. Aquaculture 78: 349-363.

23. Kukkonen, J.V., Punta, E., Koponen, P., Paranko, J., Leppanen, H., Holopainen, I.J. and Hyvarinen, H. 1999. Biomarker responses by crucian carp (Carassius carassius) living in a pond of secondary treated pulp mill effluent. Water Sci. Technol. 40: 123-130.

24. Kuwahara, S., Mizukami, T., Omura, M., Hagihara, M., Linuma, Y., Shimizu, Y., Tamada, H., Tsukamoto, T., Nishida, T. and Sasaki, F. 2000. Seasonal changes in the hypothalamo- 
pituitary-testes axis of the Japanese wood mouse (Apodemus specious). Anat. Rec. 260: 366-372.

25. Lye, C.M., Frid, C.L.J., Gill, M.E. and McCormick, D. 1997. Abnormalities in the reproductive health of flounder Platichtys flesus exposed to effluent from a sewage treatment works. Mar. Pollut. Bull. 3: 34-41.

26. McMaster, M.E., Van Der kraak, G.J., Portt, C.B., Munkittrick, K.R., Sibley, P.K., Smith, I.R. and Dixon, D.G. 1991. Changes in hepatic mixed function oxygenase (MFO) activity, plasma steroid levels and age at maturity of a white sucker (Catastomus commersoni) population exposed to bleached kraft pulp mill effluent. Aquat. Toxicol. 21: 199-218.

27. Miles-Richardson, S.R., Kramer, V.J., Fitzgerald, S.D., Render, J.A., Yamini, B., Barbee, S.J. and Giesy, J.P. 1999. Effects of waterborne exposure of $17 \beta$-estradiol on secondary sex characteristic and gonads of fathead minnows (Pimephales promelas). Aquat. Toxicol. 47: 129-145.

28. Miyadi, D., Kawanabe, H. and Mizuno, N. 1976. Colored Illustration of the Freshwater Fishes of Japan. pp. 1-462, Hoikusha Publishing Co., Ltd., Osaka (in Japanese).

29. Munkittrick, K.R., Port, C.B., Van Der Kraak, G.J., Smith, I.R. and Rokosh, D.A. 1991. Impact of bleached kraft mill effluent on population characteristics, liver MFO activity, and serum steroids of the Lake Superior white sucker (Catostomas commersoni) population. Can. J. Fish. Aquat. Sci. 48: 1-10.

30. Orlando, E., Denslow, N.D., Folmar, L.C. and Guillette, J. 1999. A comparison of the reproductive physiology of largemouth bass, Micropteus salmoides, collected from the Escambia and Black Water Rivers in Florida. Environ. Health Perspect. 107: 199-204.

31. Purdom, C.E., Hardiman, P.A., Bye, V.J., Eno, N.C., Tyler, C.R. and Sumpter, J. 1994. Estrogenic effects of effluents from sewage treatment works. Chem. Ecol. 8: 275-285.

32. Solomon, G., Matsushita, K., Shimizu, M. and Nose, Y. 1985. Age and growth of rose bitterling in shin tone river. Bull. Jpn. Soc. Sci. Fish. 51: 55-62.

33. Sumpter, J. and Jobling, S. 1995. Vitellogenesis as a biomarker for estrogenic contamination of the aquatic environment. Environ. Health Prespect. 103: 173-178.

34. Van Der Kraak, G.J., Munkittrick, K.R., McMaster, M.E., Port, C.B. and Change, J.P. 1992. Exposure to bleached kraft pulp mill effluent disrupts the pituitary-gonadal axis of white sucker at multiple sites. Toxicol. Appl. Pharmacol. 115: 224-233.

35. Wester, P.W. 1991. Histopathological effects of environmental pollutants $\beta$-HCH and methyl mercury on reproductive organs in freshwater fish. Comp. Biochem. Physiol. 100: 237-239. 